\title{
ENSINO DE CIÊNCIAS NO ENSINO FUNDAMENTAL POR MEIO DE TEMAS SOCIOCIENTÍFICOS: ANÁLISE DE UMA PRÁTICA PEDAGÓGICA COM VISTA À SUPERAÇÃO DO ENSINO DISCIPLINAR
}

\section{Teaching science in elementary school through social-scientific themes: analysis of a pedagogical practice towards overcoming disciplinary education}

\author{
Juliana Viégas Mundim ${ }^{1}$. Wildson Luiz Pereira dos Santos ${ }^{2}$
}

\begin{abstract}
Resumo: Este artigo apresenta resultados de pesquisa que apontam como uma abordagem de tema sociocientífico no ensino de ciências propicia aos alunos relacionarem conhecimento científico com situações de sua vivência. A experiência foi desenvolvida em aulas de ciências naturais de uma turma do oitavo ano do Ensino Fundamental de uma escola pública do Distrito Federal. A abordagem temática visou explorar relações Ciência-Tecnologia-Sociedade (CTS) e foi desenvolvida seguindo orientações de adoção de situação de estudo e de temas geradores recomendadas na literatura de ensino de ciências. A análise dos dados sugere que estudantes que não estabeleciam vínculos entre conhecimento científico e o seu contexto de vida, passaram a perceber tal articulação após a introdução de um tema sociocientífico. Além disso, observou-se um maior interesse e participação dos alunos durante as aulas, acompanhados de uma maior compreensão do conteúdo científico explorado.
\end{abstract}

Palavras-chave: Ensino de ciências. Ensino Fundamental. CTS.

Abstract: This article presents research results which demonstrate how a socio-scientific thematic approach to science education provides students with a chance to relate scientific knowledge with everyday life. The lessons were conducted in natural science subjects in $8^{\text {th }}$ grade group of a Distrito Federal public elementary school. The aim of the thematic approach was exploring STS (ScienceTechnology-Society) relationships. The lessons were carried out according to perspectives in the science education literature about study situations and generating themes. The analysis of the data suggests that students who did not establish connections between scientific knowledge and their living context began to realize that such connections existed after the introduction of a socio-scientific theme. Besides, a greater interest and participation of students during classes was noted; and a better understanding developed of the scientific content explored.

Keywords: Science teaching. Fundamental school. STS.

\footnotetext{
${ }^{1}$ Secretaria de Estado de Educação do Distrito Federal (SEEDF). Quadra 02 MR 01, casa 04, Setor Leste. Planaltina de Goiás, GO, Brasil.73.752-020.jvmundim@gmail

${ }^{2}$ Instituto de Química, Universidade de Brasília (UnB). Brasília, DF, Brasil.
} 
Mundim, J. V.; Santos, W. L. P.

\section{Introdução}

O atual ensino de ciências nas séries finais do Ensino Fundamental reproduz uma contradição herdada do antigo ginásio, pois perpetua o tratamento disciplinar do conhecimento científico dessa época, contrariando a perspectiva de ensino para formação geral do estudante estabelecida pela atual legislação de ensino, a Lei 9.394/96 (BRASIL, 1996). O ginásio foi estabelecido na reforma do ensino secundário de 1942 e pela primeira Lei de Diretrizes e Bases (LDB), Lei 4.024 de 20 de dezembro de 1961 (BRASIL, 1961). Correspondia ao primeiro ciclo do ensino secundário, no qual o componente curricular ciências naturais era tratado de forma disciplinar. Ocorre que, com a Lei de Diretrizes e Bases 5.692/71 (BRASIL, 1971), houve mudanças na estrutura do ensino, e o ensino de ciências passou a ser visto na etapa final do ensino de primeiro grau, como área do conhecimento, e não como disciplina.

O ensino de primeiro grau uniu o primário e o primeiro ciclo do secundário (o ginasial), passando a ter duração de oito anos. Dentre outros objetivos, a nova organização curricular visava propiciar a formação geral fundamental e obrigatória. O currículo ficou organizado de forma que, no $1^{\circ}$ grau, a educação geral fosse exclusiva nas séries iniciais e predominantes nas finais. As matérias foram organizadas em atividades (experiências vividas), áreas de estudo (integração de conteúdos afins) e disciplinas (conhecimentos sistemáticos), de forma que, no decorrer do ensino, as atividades e áreas de estudos fossem predominantes no $1^{\circ} \mathrm{grau}$ e as disciplinas no $2^{\circ}$ grau.

Esse caráter geral permaneceu parcialmente na atual LDB (BRASIL, 1996) e na organização curricular estabelecida pelos Parâmetros Curriculares Nacionais (PCN) - Ensino Fundamental (BRASIL, 1998a, 1998b, 1998c). A Lei 9.394/96 e os PCN estabelecem um ensino voltado para o contexto social. Dessa forma, a interpretação das informações sobre a ciência e a tecnologia requer uma compreensão dos diversos campos das ciências integrados entre si e com as questões sociais. Em síntese, a Lei 9.394/96 e os PCN expressam preocupação em promover uma educação geral voltada para a aprendizagem e para o exercício da cidadania (BRASIL, 1998a). A organização dos conteúdos por áreas de ensino, o tratamento interdisciplinar e a transversalidade de temas estabelecidos nesses documentos buscam dinamizar e dar significado ao ensino de ciências.

Os PCN estabelecem referenciais para orientar as políticas de ensino para a formação para a cidadania e o direito a aprender, comum a todos os alunos. Suas orientações buscam respeitar as diferenças regionais e a diversidade cultural presente no país, possibilitando adaptações para suprir as necessidades educacionais de cada região. Os seus objetivos gerais focalizam tanto os aspectos necessários ao desenvolvimento do aluno para a cidadania, quanto orientam na escolha dos conteúdos a serem trabalhados. Os conteúdos propostos são organizados em áreas de conhecimento para atenderem aos objetivos gerais do Ensino Fundamental, dentre as quais se encontram as ciências naturais. O documento estabelece, além dos conteúdos das várias áreas de conhecimento, questões sociais que interferem na vida do aluno, que são apresentadas como temas transversais.

Os temas transversais caracterizam-se pela proposta de uma educação para a vida, com desenvolvimento de valores humanistas e indivíduos críticos e solidários (YUS, 1998). Esses temas compreendem um conjunto de questões não ligado às disciplinas escolares, mas que pode ser comum a todas, fazendo uma ponte entre o conhecimento cotidiano do aluno e 
o conhecimento disciplinar ensinado na escola. Os temas transversais apontados nos PCN são: ética, saúde, meio ambiente, pluralidade cultural, orientação sexual, trabalho e consumo (BRASIL, 1998b).

De acordo com os PCN da área de ciências naturais (BRASIL, 1998c), o conhecimento científico deve estar vinculado à tecnologia e às questões sociais e ambientais para que a ciência seja entendida como uma produção humana. Propõe-se, no documento, que a área de ciências naturais seja dividida em eixos temáticos para que os conteúdos não sejam fragmentados, utilizando-se uma perspectiva interdisciplinar, para a integração entre os conhecimentos físicos, químicos, biológicos, tecnológicos, sociais e culturais. Os eixos temáticos são: vida e ambiente, ser humano e saúde, tecnologia e sociedade, terra e universo. Essa organização tem a intenção de relacionar os diferentes conceitos, atitudes, valores e procedimentos de cada etapa do processo escolar. Dessa forma, percebe-se que a organização proposta enfatiza a importância do ato de aprender e de saber usar o conhecimento científico.

Destaca-se, ainda, que essa organização enfatiza a compreensão dos diversos campos da ciência, não como disciplinas isoladas, mas integrados entre si e com as questões sociais. Porém, muitos fatores ainda dificultam uma educação nessa perspectiva, tais como: a permanência da organização do currículo de forma disciplinar (herança do curso ginasial), que conserva a fragmentação das áreas; a dificuldade em discutir temas relacionados a questões sociais; o distanciamento entre o conhecimento teórico e a realidade do aluno; além de fatores relacionados à estrutura das escolas, aos materiais didáticos, à formação dos professores; entre outros.

Enquanto a legislação educacional procurou avançar em termos de concepção curricular, na prática de sala de aula, o ensino de ciências continua de forma disciplinar como se tinha no antigo ginásio. Em geral, o currículo de ciências, em muitas escolas, é desenvolvido como se, no sexto ano, fosse uma disciplina isolada de Geociências; no sétimo ano, fossem disciplinas de Biologia na área de zoologia e botânica; no oitavo ano, disciplina de Biologia na área de anatomia e fisiologia humana; e, no nono ano, as disciplinas Química e Física.

Com esse currículo e com uma abordagem inadequada, o ensino de ciências naturais pouco tem contribuído para o aprendizado do conhecimento científico ou para a compreensão daquilo que está sendo estudado. Chassot (2000) tem destacado que os estudantes concluem a Educação Básica com um escasso conhecimento sobre a ciência, pois muito pouco do que é ensinado sobre a ciência na Educação Básica é aproveitado. Delizoicov, Angotti e Pernambuco (2002) consideram que o ensino convencional de ciências naturais conserva uma visão acabada e estática da ciência, ao que denominam "senso comum pedagógico", caracterizado pela transmissão mecânica de informações. Ainda de acordo com Bizzo (1998), estudos têm demonstrado que o ensino de ciências tem sido ineficiente, reduzindo-se a uma repetição e memorização de nomes e fatos sobre os produtos da ciência.

Visando contribuir para a superação desse quadro do ensino de ciências, no presente artigo, apresentamos resultados de uma experiência pedagógica no ensino de ciências naturais, desenvolvida por meio de uma abordagem temática que visou integrar o conhecimento científico com o contexto social dos estudantes (MUNDIM, 2009). As atividades realizadas se diferenciam da abordagem clássica disciplinar de conteúdos descontextualizados que ainda caracterizam o ensino de ciências no Ensino Fundamental, e os resultados apontam aspectos positivos alcançados. 
Mundim, J. V.; Santos, W. L. P.

\section{A abordagem de temas sociocientíficos no ensino de ciências}

Muitas pesquisas têm apresentado discussões a respeito da educação científica para a formação da cidadania (CACHAPUZ; PRAIA; JORGE, 2004; KRASILCHIK; MARANDINO, 2004; SANTOS; SCHNETZLER, 1997). A educação científica para a cidadania propõe que a compreensão do conhecimento científico ocorra juntamente com o desenvolvimento da capacidade de pensar, para a tomada de decisões responsáveis sobre as situações que envolvem a ciência, a tecnologia e a sociedade (SANTOS; SCHNETZLER, 1997). Esses propósitos se coadunam com os objetivos do desenvolvimento da autonomia, do senso crítico, da capacidade de comunicação e de tomada de decisão responsável, que têm sido encontrados no que se tem chamado de alfabetização científica (AULER; DELIZOICOV, 2001; CHASSOT, 2000; FOUREZ, 1994), e que Santos (2007) denomina como letramento científico, cuja intenção é enfatizar a função social do ensino de ciências.

Esses propósitos que caracterizam a formação da cidadania e fundamentam as orientações legais para o ensino de ciências naturais no Ensino Fundamental também são encontrados no movimento de educação científica com foco nas inter-relações Ciência-TecnologiaSociedade (CTS). Aikenhead $(1994,2006)$ reúne os objetivos para o ensino CTS a partir de trabalhos que utilizaram esse enfoque. Entre os objetivos, podem ser destacados: aumentar o interesse geral no entendimento sobre ciência, sobretudo para aqueles estudantes desencorajados pelo currículo tradicional; suprir a falta de crítica no currículo tradicional; desenvolver capacidades intelectuais, como pensamento crítico, razão lógica, resolução de problemas e tomada de decisão; preparar para a cidadania etc.

No Brasil, o aparecimento de cursos com a denominação CTS só começou a ocorrer na década de 1990, a partir do desenvolvimento de pesquisas e da publicação de artigos sobre o assunto (SANTOS, 2008). Em revisão de trabalhos referentes a iniciativas de inclusão dos pressupostos CTS no ensino de ciências, Auler (2007) considera que ainda não há coerência quanto ao currículo, objetivos e implementação dessa perspectiva em escolas, fato que demonstra que a ênfase CTS na educação no Brasil ainda está em desenvolvimento.

Uma questão bastante discutida com relação ao ensino de ciências CTS refere-se ao entendimento sobre tal enfoque. De acordo com Santos e Mortimer (2000), muito do que é considerado como ensino de ciências CTS não passa de inserções de aplicações CTS como meio de fazer relações pontuais entre o conteúdo científico e o cotidiano, em uma perspectiva meramente de motivação. Em outros currículos CTS, a organização é disciplinar e alguns temas CTS são introduzidos sem mudar a estrutura curricular, é o que se tem classificado como enxertos de CTS (WAKS, 1990; LUJÁN LÓPEZ; LÓPEZ CEREZO, 1996). Pode-se afirmar, assim, que nem todas as propostas de ensino que se dizem CTS estão centradas em discussões sobre as inter-relações entre ciência, tecnologia e sociedade, ou são organizadas a partir de temas CTS.

O ensino de ciências com foco real em CTS envolve tanto conteúdo científico quanto conteúdo CTS, podendo combinar tanto ciência e tecnologia quanto ciência e sociedade ou qualquer outra relação envolvendo os conhecimentos sobre ciência, tecnologia e sociedade. Uma característica central desse ensino CTS está na sua organização por meio de temas (AIKENHEAD, 1994; SOLOMON, 1994; YAGER, 1993; SANTOS; MORTIMER, 2000; SANTOS; SCHNETZLER, 2010). Os temas de natureza CTS, também denominados temas socio- 
científicos (SANTOS; MORTIMER, 2009), envolvem questões referentes à ciência e tecnologia que têm grande impacto na sociedade. São características de um tema sociocientífico: relacionar-se a ciência; envolver formação de opinião e escolhas; ter dimensão local, nacional ou global; envolver discussão de valores e ética; estar relacionado à vida; envolver discussão de benefícios, riscos e valores, entre outras (RATCLIFFE; GRACE, 2003). Assim, a abordagem de temas tem sido sugerida para vincular o conhecimento científico à tecnologia e às questões sociais e ambientais, buscando dar significado e relevância ao conteúdo científico.

A organização curricular com enfoque CTS difere da organização clássica do ensino de ciências (SANTOS; MORTIMER, 2000; SANTOS; SCHNETZLER, 2010). No ensino CTS, ao invés dos conteúdos serem ordenados por unidades programáticas centradas em temas canônicos da ciência (por exemplo, geociências, zoologia, botânica, corpo humano, química, física), eles são organizados a partir de temas sociocientíficos (por exemplo, água, saúde, alimentação, poluição etc.). Deve-se destacar, todavia, que, no enfoque CTS, procura-se respeitar, também, uma ordem psicológica da aprendizagem conceitual. Assim, a seleção e ordenação dos temas sociocientíficos é feita considerando-se o grau de complexidade dos conceitos científicos vinculados aos temas, de acordo com o desenvolvimento cognitivo do aluno. A diferença central está no fato de que os conteúdos são apresentados de forma integrada aos temas, e não de maneira fragmentada e descontextualizada, que caracteriza a abordagem clássica do atual ensino de ciências.

A abordagem de temas CTS tem sido proposta para o Ensino Fundamental. Andrade e Carvalho (2002) apresentaram um trabalho realizado com alunos do $7^{\circ}$ ano, a partir do tema Projeto Pró-Álcool. Nesse trabalho, buscou-se observar as concepções e o posicionamento dos alunos frente aos impactos da ciência e tecnologia sobre a sociedade. Tendo como referência a proposta de ensino CTS e a aprendizagem centrada em eventos, Samagaia e Peduzzi (2004) apresentaram a elaboração e aplicação de um módulo didático para a abordagem do tema da Física Moderna para aulas de ciências do $9^{\circ}$ ano: o desenvolvimento e utilização das bombas nucleares que destruíram Hiroshima e Nagasaki.

Recomendações para abordagem temática no ensino de ciências naturais têm sido feitas por Delizoicov, Angotti e Pernambuco (2002), e por Maldaner e Zanon (2004). Delizoicov, Angotti e Pernambuco (2002) propõem um ensino centrado no que denominam de temas geradores; já Maldaner e Zanon (2004) consideram o enfoque temático centrado no que denominam de situação de estudo.

As estratégias de trabalho utilizando temas geradores apresentadas por Delizoicov, Angotti e Pernambuco (2002) constituem uma proposta de ensino na qual os conteúdos a serem trabalhados são escolhidos com base em um tema. O tema é escolhido conforme a relevância e emergência que possuem no contexto do aluno. A partir do tema, os alunos são levados a problematizar ou questionar o conhecimento que têm inicialmente (senso comum ou cultura primeira), até chegarem à necessidade do uso do conhecimento científico (conhecimento sistematizado ou culturalmente elaborado) para a explicação das situações levantadas. Ou seja, o conceito científico é o ponto de chegada, e o tema, o ponto de partida no processo educacional. Segundo esses autores, essa abordagem deve seguir três passos básicos. No primeiro, os alunos são incentivados a pensar e a problematizar sobre situações relacionadas com o tema. Em seguida, é realizada a organização do conhecimento. O professor desenvolve a conceituação necessária para o entendimento científico dos problemas levantados e propõe a 
realização de atividades e exercícios. A aplicação do conhecimento estudado acontece por último e é conduzida tanto para se estudarem as situações iniciais levantadas pelos alunos, quanto para explicar outras situações que podem ter surgido durante a aula.

A situação de estudo (SE) é uma proposta de organização do ensino de ciências por meio da articulação dos conteúdos curriculares entre si e os saberes trazidos das vivências dos alunos (MALDANER; ZANON, 2004; MALDANER et al., 2007). Nesse sentido, a SE é centrada nas situações reais vividas pelos estudantes. Durante uma SE, há articulação entre o conhecimento cotidiano dos alunos e o conhecimento científico. Os conceitos e significados são construídos tendo como ponto de partida a experiência de vida dos alunos, que são incentivados a repensar e reconstruir suas concepções, ampliando a visão de mundo a partir dos processos interativos estabelecidos na sala de aula. A vivência social dos alunos torna-se o meio facilitador da interação pedagógica.

\section{Procedimentos metodológicos}

Nesta investigação, a pesquisadora acompanhou uma turma do $8^{\circ}$ ano de ciências naturais do Ensino Fundamental durante um ano letivo. No primeiro semestre, a pesquisadora observou as aulas e aplicou questionários para os alunos. No segundo semestre, com base nas observações e nos resultados preliminares, a pesquisadora desenvolveu, com a professora da turma, uma experiência pedagógica de abordagem temática, e produziu dados para identificar como os alunos passaram a perceber a relação entre o conteúdo estudado e situações de sua vivência.

A pesquisa envolveu três etapas: a seleção do local e da turma, a observação das aulas e o desenvolvimento de atividades para abordagem do tema sociocientífico. Foi selecionada uma escola pública do Distrito Federal, da região urbana da cidade de Planaltina, próxima do local de trabalho da pesquisadora, e que tivesse um professor que aceitasse o desenvolvimento do trabalho. A escolha da turma seguiu a preferência da professora que se dispôs a participar da pesquisa.

A observação da turma ocorreu para estabelecer maior contato entre pesquisadora, professora e alunos, e para a identificação da dinâmica estabelecida na turma. Nessa etapa, foi realizada uma entrevista com 18 alunos, selecionados por sorteio, para identificar suas percepções sobre as aulas de ciências. Os alunos foram entrevistados em grupos focais com seis componentes cada. Depois, foi aplicado um questionário para toda a turma. A aplicação do questionário teve a finalidade de identificar e reafirmar as percepções dos alunos obtidas na entrevista, considerando que, durante a entrevista, alguns alunos não se manifestaram. $O$ questionário e a entrevista foram constituídos pelas mesmas questões: Qual a sua opinião sobre a escola? Você tem o hábito de estudar? Por que você estuda? Qual a importância de estudar ciências? Que matérias você gosta de estudar, por qual motivo? O que poderia melhorar nas aulas de ciências?

Em seguida, ocorreu o planejamento das atividades pedagógicas para inclusão da abordagem do tema sociocientífico nas aulas de ciências. O planejamento foi realizado juntamente com a professora da turma, utilizando-se opiniões presentes no questionário e entrevista com os alunos, e foi fundamentado no referencial teórico anteriormente apresentado. 
O tema sociocientífico desenvolvido foi "alimentação e vida saudável”. Esse tema foi escolhido por permitir uma ampla discussão dos conceitos relacionados à ciência, à tecnologia e à sociedade, e por ter relação com o conteúdo que estava sendo desenvolvido na turma. Além do conhecimento científico referente à nutrição, também foram abordadas questões relacionadas às tecnologias de produção, armazenamento, beneficiamento de alimentos; à falta de alimentos; e aos efeitos da alimentação para o ser humano. Dessa forma, o tema permitiu a organização de uma sequência de atividade de ensino de ciências que envolveu interações entre o campo social, o tecnológico e o científico, atendendo, assim, a característica central da educação científica CTS.

As aulas foram organizadas procurando seguir os passos para uso dos temas geradores propostos por Delizoicov, Angotti e Pernambuco (2002): problematização inicial, organização do conhecimento e aplicação do conhecimento. Foram priorizadas atividades que incentivassem o pensamento e o senso crítico dos alunos, como: discussões em grupo, vídeos, experiências, trabalhos em grupo, palestra com profissional da área de nutrição, textos para a discussão de temas sociais ligados ao conteúdo científico, entre outros. A ação pedagógica envolvendo a abordagem do tema sociocientífico foi desenvolvida em 40 aulas.

A produção dos dados ocorreu: com a aplicação de questionário e entrevista durante o período de observação, com gravação em vídeo das aulas, com registro de observações em diário de campo feito pela pesquisadora, com a coleta de atividades desenvolvidas pelos alunos em sala de aula (atividade 1 - O lanche da escola, atividade 2 - Avaliação bimestral e atividade final), com a realização de entrevista com a professora e com a realização de entrevista e aplicação de questionário com os alunos após o encerramento das atividades pedagógicas.

$\mathrm{Na}$ análise dos dados, procurou-se observar indicadores de desempenho da ação pedagógica desenvolvida com o tema sociocientífico, quanto à compreensão do conhecimento científico pelos estudantes e quanto à capacidade de refletirem e aplicarem o conhecimento científico estudado em situações do cotidiano.

\section{Análise e discussão dos resultados}

\section{A observação das aulas}

Nos três primeiros meses do primeiro semestre, a professora abordou os seguintes conteúdos: células, tecidos, órgãos e nutrientes dos alimentos.

De acordo com a observação da pesquisadora, as aulas, em geral, foram desenvolvidas seguindo momentos de explicação, de realização de atividades, de orientação da turma e correção das atividades. Os procedimentos adotados nas aulas observadas pela pesquisadora estão sumarizados no Quadro 1.

Os momentos de explicação do conteúdo científico ocorriam de forma expositiva. Os alunos participavam pontualmente com uma interação do tipo pergunta do aluno - resposta do professor ou pergunta do professor - resposta do aluno, sem maior aprofundamento por parte de ambos. 
Mundim, J. V.; Santos, W. L. P.

Quadro 1. Aulas desenvolvidas durante o período de observação

\begin{tabular}{|c|l|}
\hline Aula & \multicolumn{1}{c|}{ Atividades desenvolvidas } \\
\hline 1 a 4 & $\begin{array}{l}\text { - Revisão do conteúdo referente aos tecidos (adiposo e cartilaginoso). } \\
\text { - Orientação quanto ao comportamento da turma. } \\
\text { - Explicação sobre tecido muscular, leitura do livro, resolução e correção de exercícios do livro. }\end{array}$ \\
\hline 5 a 9 & $\begin{array}{l}\text { - Resolução de atividade no quadro. } \\
\text { - Demonstração sobre tecidos utilizando pedaços de carne de frango, de boi e porco e as } \\
\text { vísceras desses animais. }\end{array}$ \\
\hline 10 a 14 & $\begin{array}{l}\text { - Realização de leitura, resumo do texto e de atividades do livro. } \\
\text { - Correção de atividade no caderno. } \\
\text { - Divisão da turma para realização de trabalho sobre os tipos de nutrientes. } \\
\text { - Apresentação dos trabalhos pelos alunos. } \\
\text { - Promoção de um piquenique em sala de aula com alimentos trazidos pelos alunos. }\end{array}$ \\
\hline 15 a 19 & $\begin{array}{l}\text { - Considerações da professora sobre os trabalhos apresentados na aula e sobre o } \\
\text { comportamento da turma durante o desenvolvimento do trabalho. } \\
\text { - Distribuição de texto para a turma e divisão em grupos para realizar atividade de debate. } \\
\text { - Considerações da professora sobre problemas ocorridos com a turma naquele dia. }\end{array}$ \\
\hline 20 a 22 & $\begin{array}{l}\text { - Apresentação dos trabalhos. } \\
\text { - Promoção de debate entre os grupos, e considerações da professora sobre a atividade } \\
\text { desenvolvida e sobre o comportamento da turma durante a realização das atividades. } \\
\text { - Resolução de atividades do livro, esclarecimento de dúvidas dos alunos sobre as questões e } \\
\text { correção das atividades. }\end{array}$ \\
\hline
\end{tabular}

Fonte: Elaborado pelos autores

Alguns momentos eram reservados para a orientação da turma (organização da sala), informações sobre os acontecimentos da escola e da própria disciplina (avaliações, atividades, trabalhos, comportamento etc.). Os alunos tinham um comportamento pouco satisfatório em termos de disciplina, fazendo a professora interromper as aulas para conversar sobre a dificuldade de trabalhar na turma. Esse comportamento trouxe prejuízos para a aprendizagem dos alunos durante grande parte do ano, além de, posteriormente, também contribuir para o atraso no desenvolvimento das atividades com a abordagem temática.

A correção das atividades ocorria com a participação dos alunos, sendo que um aluno lia o enunciado da questão ou pergunta e dois ou três liam a resposta. Em seguida, a professora fazia um comentário sobre as respostas dos alunos e reafirmava a resposta correta. Geralmente, a professora incentivava a participação dos alunos, mas o incentivo era reduzido a momentos de pergunta e resposta, nos quais a professora respondia e finalizava o assunto.

A professora realizou três atividades de culminância do conteúdo tratado nas aulas. A primeira atividade, preparada para encerrar o conteúdo sobre órgãos e tecidos, consistiu em uma exposição de fatias de carne (frango, porco e boi) para demonstrar os vários tipos de órgãos e tecidos existentes. A segunda atividade, realizada para contextualizar as primeiras considerações sobre os tipos de nutrientes, consistiu em fazer um piquenique em sala com diversos tipos de alimentos e fazer considerações sobre seus nutrientes. A terceira atividade, com a mesma finalidade da segunda, consistia em uma leitura de texto seguida de debate entre grupos sobre qual nutriente seria mais importante para o ser humano. 
A análise da entrevista e do questionário realizados com os alunos no primeiro semestre, durante o período de observação das aulas, demonstrou que o interesse pela disciplina de ciências naturais ocorria devido à professora ser agradável e ter um bom relacionamento com os alunos, o que não ocorria com outros professores. Os três grupos entrevistados e 20 de 31 alunos que responderam ao questionário compartilharam dessa opinião. As palavras de uma aluna durante a entrevista exemplificam essa constatação: "quando a professora é legal a gente acaba gostando da disciplina". Os comentários dos demais alunos demonstravam claramente essa mesma percepção de que o interesse pelas aulas de ciências estava mais relacionado à relação positiva que eles tinham com a professora.

Durante a entrevista, quando cada grupo foi questionado sobre a motivação ou a importância para o estudo de ciências, nenhum aluno manifestou percepção entre o que estudava e situações de sua vivência, ou seja, para eles o conhecimento científico estudado parecia não ter grande importância ou relevância. Os alunos dos três grupos deixaram claro que estudavam para passar de ano, ou porque os pais obrigavam, ou, mesmo, porque tinham de estudar.

Diante dessa constatação, foi desenvolvida uma sequência de atividades pedagógicas com uso de um tema sociocientífico no segundo semestre, e foram produzidos dados para identificar se os alunos passaram a ter compreensão do conhecimento científico e a fazer a articulação do conteúdo estudado com situações do cotidiano.

\section{A abordagem do tema sociocientífico}

O tema sociocientífico desenvolvido foi "alimentação e vida saudável". A atividade pedagógica contemplou os tópicos programáticos referentes aos grupos e funções dos alimentos; às medidas de higiene e conservação dos alimentos; aos sistemas digestório, circulatório, respiratório e locomotor. O tema foi trabalhado em quatro etapas: os alimentos, nutrição do corpo, atividades físicas e saúde e atividade final (Quadro 2).

A primeira etapa foi desenvolvida em 18 aulas. As aulas dessa etapa ocorreram com bastante dificuldade devido: à ausência da professora em alguns dias, que foi substituída pela pesquisadora; à constante falta de outros professores, que faziam com que fosse necessária a antecipação do horário da aula, concomitante com outras aulas; e ao comportamento da turma que, bastante agitada, dificultou o desenvolvimento das atividades planejadas. Essas situações atrapalharam o andamento das aulas, provocando mudanças drásticas no planejamento inicial e dificultando a realização de atividades, principalmente aquelas relacionadas aos debates e à exposição de ideias que foram interrompidas por falta de aulas ou foram conduzidas com dificuldade, devido a os alunos apresentarem comportamento com pouca atenção e de não saberem ouvir o outro.

Apesar das dificuldades, essa primeira etapa apresentou uma mudança positiva nas aulas: o aumento da participação dos alunos. Os alunos que, durante o período de observação, participavam de forma pontual com cinco ou seis intervenções por aula, sobretudo durante a correção de atividades, aumentaram significativamente esse número, chegando aproximadamente entre vinte e trinta intervenções nas aulas. Fato possivelmente desencadeado pela mudança na organização do currículo e no desenvolvimento das atividades referentes à abordagem do tema sociocientífico. A identificação do número de intervenções foi feita na análise dos vídeos das aulas gravadas. 
Mundim, J. V.; Santos, W. L. P.

Quadro 2. Aulas desenvolvidas durante a abordagem do tema Alimentação e vida saudável

\begin{tabular}{|c|c|c|}
\hline \multicolumn{3}{|r|}{ Alimentação e vida saudável } \\
\hline Etapas & Aulas & Atividades desenvolvidas \\
\hline \multirow{5}{*}{$\begin{array}{c}\text { Os } \\
\text { alimentos }\end{array}$} & 01 a 04 & $\begin{array}{l}\text { - Sondagem com os alunos sobre a alimentação diária; montagem de cardápio; } \\
\text { formação de grupos para pesquisar sobre os nutrientes presentes nos alimentos e } \\
\text { sobre conservação dos alimentos. } \\
\text { - Apresentação da pesquisa realizada por cada grupo. }\end{array}$ \\
\hline & 05 a 08 & $\begin{array}{l}\text { - Realização de atividades sobre alimentos e suas funções; explicação sobre os rótulos } \\
\text { das embalagens dos alimentos; explicação sobre conservação, limpeza, preparação e } \\
\text { higiene dos alimentos e doenças relacionadas, principalmente verminoses. }\end{array}$ \\
\hline & 09 e 10 & - Realização de Palestra com uma nutricionista sobre Alimentação e vida saudável. \\
\hline & 11 a 14 & $\begin{array}{l}\text { - Discussão e atividade sobre o lanche da escola. } \\
\text { - Realização de atividade sobre o percentual de nutrientes nos alimentos. }\end{array}$ \\
\hline & 15 a 18 & $\begin{array}{l}\text { - Explicação sobre reaproveitamento de alimentos: leitura de textos e atividade para ser } \\
\text { realizada em casa junto com a família. } \\
\text { - Apresentação dos resultados da atividade das aulas anteriores. } \\
\text { - Avaliação bimestral. }\end{array}$ \\
\hline \multirow{3}{*}{$\begin{array}{l}\text { Nutrição } \\
\text { do corpo }\end{array}$} & 01 a 04 & $\begin{array}{l}\text { - Realização de estudo sobre a nutrição do corpo, com pesquisa nos livros para } \\
\text { responder a um questionário. } \\
\text { - Apresentação de vídeo sobre o sistema digestório e discussão em grupo sobre o tema } \\
\text { "organismos encontrados em nosso intestino". }\end{array}$ \\
\hline & 05 a 08 & - Realização de experiência sobre digestão das gorduras e absorção de proteínas. \\
\hline & 09 a 14 & $\begin{array}{l}\text { - Apresentação de vídeo sobre o coração; realização da atividade "Bate-bate coração"; e } \\
\text { realização de entrevista na comunidade sobre o tema "Doenças cardiovasculares". } \\
\text { - Realização de atividade sobre a produção de urina. } \\
\text { - Apresentação de vídeo sobre a Respiração e realização de atividade sobre as } \\
\text { diferenças entre o ar inspirado e o ar expirado pelos pulmões. } \\
\text { - Correção das atividades realizadas nas aulas anteriores. }\end{array}$ \\
\hline $\begin{array}{l}\text { Atividades } \\
\text { físicas e } \\
\text { saúde }\end{array}$ & 01 e 02 & $\begin{array}{l}\text { - Realização de palestra com profissional de educação física sobre o tema: atividade } \\
\text { física e saúde. }\end{array}$ \\
\hline \multirow{2}{*}{$\begin{array}{l}\text { Atividade } \\
\text { final }\end{array}$} & 01 a 04 & $\begin{array}{l}\text { - Orientação da professora para realização da atividade; organização dos grupos e } \\
\text { escolha do tipo de apresentação e preparação das apresentações pelos grupos. }\end{array}$ \\
\hline & 05 e 06 & - Apresentação final \\
\hline
\end{tabular}

Fonte: Elaborado pelos autores

A segunda etapa foi desenvolvida em quatorze aulas. Nessa etapa, o objetivo foi levar os alunos a compreenderem como os alimentos são transformados pelo organismo. Para isso, foram abordados os sistemas circulatório, digestório e respiratório. As aulas dessa etapa ocorreram de maneira regular, não houve ausência da professora, e os alunos já estavam mais habituados à nova dinâmica estabelecida pela abordagem do tema sociocientífico. O planejamento previsto para as aulas foi mantido, os alunos se apresentaram mais dispostos para a 
realização das atividades, e ocorreu uma significativa melhora no comportamento da turma em geral. $\mathrm{O}$ único problema continuou sendo a interrupção das aulas, por motivos diversos, mas que ocorreu com menor frequência.

A terceira etapa do planejamento sofreu bastante alteração, com relação ao previsto inicialmente, devido à falta de aula na turma. Nas duas aulas dessa etapa, os alunos participaram de uma palestra com uma professora de educação física, que abordou o tema "atividade física e vida saudável". O fato de maior relevância foi a participação dos alunos durante a palestra: dezessete intervenções. Situação que demonstra o interesse dos alunos por assuntos relacionados ao cotidiano.

A quarta etapa, a atividade final, teve o objetivo de fazer uma culminância entre todo o conteúdo trabalhado durante o desenvolvimento da atividade pedagógica. Os alunos deveriam desenvolver uma maneira de informar as pessoas, o público geral, sobre o tema "Alimentação e vida saudável". Eles poderiam escolher a maneira que melhor lhes conviesse para realizar esta atividade: folder, teatro, jornal, poesia, história em quadrinhos etc.; e o trabalho deveria abordar o conhecimento estudado. Essa etapa teve bastante aceitação dos alunos, que apresentaram muito empenho na realização da atividade proposta. Os alunos demonstraram criatividade, compreensão do conteúdo científico tratado no período e, em várias situações, capacidade de relacionar situações do cotidiano e conteúdo científico, e vice-versa.

\section{Os dados produzidos}

A articulação entre o conteúdo estudado e as situações do cotidiano foi observada durante o desenvolvimento da atividade pedagógica. Três atividades desenvolvidas com os alunos permitiram essa constatação: atividade 1 (o lanche da escola), atividade 2 (avaliação bimestral) e atividade final.

$\mathrm{Na}$ realização das atividades um e dois, os alunos demonstraram ter compreensão quanto à aplicação do conhecimento científico e às situações do cotidiano. Veja, no Quadro 3, algumas respostas de alunos às atividades um e dois.

Quadro 3. Relação Atividade 1 e 2 /Respostas dos alunos

\begin{tabular}{|l|l|}
\hline \multicolumn{1}{|c|}{ Atividade } & \multicolumn{1}{c|}{ Respostas dos alunos } \\
\hline $\begin{array}{l}\text { Atividade 1: Analisar o lanche da } \\
\text { escola em relação aos nutrientes e } \\
\text { indicar como ele deveria ser para } \\
\text { se ter uma alimentação saudável. }\end{array}$ & $\begin{array}{l}\text { - O lanche não apresenta os nutrientes necessários para uma boa } \\
\text { alimentação, por não ter frutas e verduras; por ser frito e gorduroso, por } \\
\text { ser fraco e com pouca variedade. } \\
\text { - Sugestões: ter mais frutas, folhas, verduras, sucos naturais; menos } \\
\text { frituras e doces; comida mais colorida; comida variada; e menos sal. }\end{array}$ \\
\hline $\begin{array}{l}\text { Atividade 2: O cardápio elaborado } \\
\text { por você no início das aulas supre } \\
\text { as necessidades nutricionais } \\
\text { diárias? }\end{array}$ & $\begin{array}{l}\text { Resposta aluno 1: "Sim, pois tem ferro, fibras, carboidratos, vitaminas, } \\
\text { nutrientes, gorduras". } \\
\text { Resposta aluno 2: "Não. Coloquei as coisas que eu gosto. Só tem } \\
\text { fritura, carne, massa." } \\
\text { Resposta aluno 3: "Mais ou menos. Porque algumas das comidas que } \\
\text { eu escolhi fazem bem, por outro lado os outros fazem mal. Mais os } \\
\text { que fazem bem suprem as necessidades diárias". }\end{array}$ \\
\hline
\end{tabular}

Fonte: Elaborado pelos autores 
Durante a realização da atividade final, os estudantes demonstraram capacidade de aplicar o conhecimento abordado durante as aulas com grande riqueza de conteúdo e informações, e, ainda, uma disposição em discutir e fazer escolhas, conforme pode-se depreender em trechos da atividade final (Quadro 4).

Quadro 4. Trechos das apresentações dos alunos na atividade final

\begin{tabular}{|c|c|c|}
\hline Apresentação teatral (grupo 1) & Poesia (grupo 4) & Apresentação teatral (grupo 5) \\
\hline $\begin{array}{l}\text { Cigana: - Eu estou vendo aqui (na } \\
\text { mão) e aqui (na barriga) que você } \\
\text { leva uma vida sedentária, que } \\
\text { você não faz atividades físicas. } \\
\text { Palhaço: - } A \text { h, isso é verdade, } \\
\text { pega mais cem reais. } \\
\text { Cigana: - Eu vejo também que } \\
\text { você não come legumes amarelos. } \\
\text { Seu cabelo tá todo quebrado. }\end{array}$ & $\begin{array}{l}\text { A vida não se resume a } \\
\text { comer, comer, comer... } \\
\text { Temos que praticar } \\
\text { exercícios para podermos } \\
\text { nos desenvolver } \\
\text { E a aula de ciências } \\
\text { podermos aprender. }\end{array}$ & $\begin{array}{l}\text { Repórter: Bom dia. Queremos saber o } \\
\text { que devemos fazer para ter uma vida } \\
\text { saudável? } \\
\text { Nutricionista: O primeiro passo para ter } \\
\text { uma vida saudável é evitar frituras e } \\
\text { comidas gordurosas e uma vida } \\
\text { estressante. Dar preferência para as } \\
\text { frutas. [...] E fazer caminhada de manhã } \\
\text { ou tarde. }\end{array}$ \\
\hline
\end{tabular}

Fonte: Elaborado pelos autores

A professora também ressaltou que os alunos passaram a fazer a relação entre o que eles estavam estudando e situações do cotidiano: "hoje eles sabem por que têm que comer bem e quais alimentos fazem bem. Eles sabem associar situações da vida deles com aquilo que eles aprenderam. Sabem fazer a relação" (professora - entrevista final). Essa situação é reforçada em relato registrado em diário de campo: a professora disse que, antes da realização da intervenção pedagógica, os alunos tinham resistência em consumir o lanche servido na escola quando eram frutas (banana, maçã, melancia etc.), e que, durante a atividade pedagógica, os alunos passaram a ter uma aceitação melhor do lanche.

Os alunos apresentaram evolução quanto à compreensão do conteúdo científico, como pode ser notado nas respostas das atividades um, dois e nas apresentações da atividade final, pois souberam identificar os nutrientes presentes ou não nos alimentos e descreveram como deveria ser uma alimentação saudável.

A entrevista e o questionário final com os alunos reforçam essa situação: para os alunos, o fato de poderem participar e falar, e não apenas fazerem cópias, possibilitou maior compreensão do conteúdo: "Hoje tem que aprender e passar as ideias pros demais colegas, agora participa mais. Antes era mais copiar e escutar. Hoje tem que aprender para depois falar" (aluno - entrevista final). A professora também destacou que os alunos aprenderam e não só decoraram o conteúdo: "eles aprenderam. Aprender é uma coisa, decorar é outra. Não é decoreba. Superaram a prática de decorar e repetir. Aprenderam utilizando situações da vida deles" (professora - entrevista final).

Em síntese, podemos destacar que a abordagem do tema sociocientífico proporcionou:

- maior participação dos alunos nas aulas: as gravações das aulas em vídeo permitiram notar que, no primeiro semestre, as participações se limitavam a entre cinco a sete intervenções dos alunos durante as correções de exercícios ou quando a atividade iria ser avaliada. No 
segundo semestre, a participação foi aumentando gradualmente e, em alguns eventos, houve uma considerável participação dos alunos, chegando a ocorrer entre 15 a 30 intervenções; e

- melhor rendimento no aprendizado: a melhora no rendimento dos alunos foi destacada pelos próprios alunos e pela professora ao responderem sobre as mudanças ocorridas nas aulas de ciências. Ambos consideraram que, durante o período de realização da atividade pedagógica, os alunos melhoraram o desempenho na disciplina, pois a maneira com que as aulas foram desenvolvidas possibilitou maior compreensão do conteúdo. "A mudança foi boa, a gente aprendeu e se interessou mais, melhorou a nota" (aluna - entrevista final). "A aprendizagem foi bem interessante. Tudo que era colocado, proposto para eles levarem para casa, $90 \%$ faziam direitinho. Teve muita mudança em relação ao primeiro semestre. Com as aulas os alunos amadureceram" (professora - entrevista final).

Esses dados evidenciam que a abordagem do tema sociocientífico possibilitou a percepção dos alunos de situações de sua vivência diária com o conteúdo científico estudado. Além disso, houve maior interesse e participação dos alunos durante as aulas, acompanhada de uma maior compreensão do conteúdo científico.

\section{Considerações finais}

O envolvimento dos alunos nas atividades desenvolvidas e a participação deles com a aplicação dos conceitos estudados evidenciam uma mudança satisfatória em relação ao significado que eles passaram a atribuir ao conhecimento científico estudado. Dessa forma, o ensino de ciências para esses alunos passou a ter uma relevância social e ajudá-los na sua formação como cidadãos.

A abordagem de tema sociocientífico propiciou integrar conteúdos científicos ao tema. Dessa forma, rompeu-se com a estrutura clássica de organização a partir dos conceitos, pois os conteúdos foram introduzidos a partir do tema. As discussões desenvolvidas envolveram reflexões sobre a influência dos meios de comunicação na alimentação e sobre como o processamento tecnológico afeta a qualidade dos alimentos, ou seja, o tema propiciou a abordagem de interações CTS. O conteúdo científico desenvolvido seguiu a orientação da situação de estudo. Foi mantido o conteúdo do currículo que vinha sendo trabalhado pela professora, o qual passou a ser relacionado com as situações de vivência dos alunos. As aulas foram organizadas também procurando seguir os passos para uso dos temas geradores propostos por Delizoicov, Angotti e Pernambuco (2002): problematização inicial, organização do conhecimento e aplicação do conhecimento.

A abordagem do tema sociocientífico iniciou com a discussão e observação de questões relacionadas ao cotidiano do aluno. Para a primeira etapa, foi solicitado aos alunos que montassem um cardápio conforme seus hábitos alimentares. Já para segunda etapa, foi feita uma sondagem com os alunos sobre como os alimentos são absorvidos pelo organismo. Ambas as atividades suscitaram a curiosidade e o interesse dos alunos, encaminhando a discussão para os passos seguintes: a organização do conhecimento por meio de leitura dos textos e pesquisas; e a aplicação do conhecimento com a realização de discussões, debates e atividades sobre o assunto. Porém, a sequência de ensino proposta na abordagem de temas geradores não pode ser desenvolvida totalmente, pois, em muitos momentos, ocorreu a falta de aulas por 
longos períodos, dificultando o encadeamento das ideias e a realização das atividades planejadas para a sequência.

A terceira e quarta etapas (atividade física e saúde e atividade final) tiveram um tratamento diferenciado, pois a terceira consistiu em uma palestra e a última foi um momento de culminância e compartilhamento de conhecimento.

Os resultados obtidos indicam que a abordagem de tema sociocientífico, por meio do uso de situação de estudo (MALDANER; ZANON, 2004) e de temas geradores (DELIZOICOV; ANGOTTI; PERNAMBUCO, 2002), é uma estratégia bastante produtiva no ensino de ciências. Ela contribuiu para que os alunos articulassem o conteúdo científico com situações de sua vivência, e aplicassem conceitos estudados em seu contexto social, como vem sendo recomendado nos PCN.

$\mathrm{Na}$ medida em que os alunos passaram a analisar a sua alimentação em termos de valor nutricional, eles começaram a decodificar o conhecimento científico e a entender o mundo em que vivem. Essas contribuições direcionam para uma formação diferenciada para o ensino de ciências na perspectiva de auxiliar os alunos a compreenderem o significado do conhecimento científico para a vida e para as relações sociais que se estabelecem no decorrer dos tempos e das sociedades.

Entendemos que, da mesma forma, os demais conteúdos de ciências naturais do Ensino Fundamental podem ser abordados por meio de temas sociocientíficos, superando a visão fragmentada que tem marcado esse ensino. Esse é um caminho para se romper a estrutura acadêmica que caracterizou o ensino ginasial que, tradicionalmente, se destinava aos filhos da elite, em um modelo de ensino propedêutico descontextualizado que servia como adorno cultural para legitimar o seu status social. Com a crescente universalização do Ensino Fundamental, está na hora de se rever o modelo de ensino de ciências para democratizar esse processo e não reproduzir antigas visões.

\section{Referências}

AIKENHEAD, G. What is STS teaching? In: SOLOMON, J.; AIKENHEAD, G. STS education: international perspectives on reform. New York: Teachers College Press, 1994. p. 169-186.

Science education for everyday life: evidence-based practice. New York: Teachers College Press, 2006.

ANDRADE, E. C. P.; CARVALHO, L. M. O Pró-Álcool e algumas relações CTS concebidas por alunos de $6^{a}$ série do ensino fundamental. Ciência \& Educação, Bauru, v. 8, n. 2, p. 167-185, 2002.

AULER, D. Enfoque ciência-tecnologia-sociedade: pressupostos para o contexto brasileiro. Ciência \& Ensino, Campinas, v. 1, p. 1-20, 2007. (Número especial).

AULER, D.; DELIZOICOV, D. Alfabetização científico-tecnológica para quê? Ensaio, Belo Horizonte, v. 3, n. 2, p. 105-116, 2001.

BIZZO, N. Ciências: fácil ou difícil? São Paulo: Ática, 1998. 
Ensino de Ciências no Ensino Fundamental ...

BRASIL. Lei 4.024 de 20 de dezembro de 1961. Fixa as Diretrizes e Bases da Educação Nacional. Brasília, 1961. Disponível em: <http://www.planalto.gov.br/ccivil_03/Leis/ L4024.htm>. Acesso em: 12 out. 2010.

Lei n. 5.692 de 11 de agosto de 1971. Fixa Diretrizes e Bases para o ensino de $1^{\circ}$ e $2^{\circ}$ graus, e dá outras providências. Brasília, 1971. Disponível em: <http:// www.planalto.gov.br/Ccivil_03/LEIS/L5692.htm>. Acesso em: 12 out. 2010.

Lei 9.394 de 20 de dezembro de 1996. Estabelece as diretrizes e bases da educação nacional. Diário Oficial da União, Brasília, 23 dez. 1996. Disponível em: <http:/ / www.planalto.gov.br/ccivil_03/Leis/L9394.htm>. Acesso em: 12 out. 2010.

. Ministério da Educação e do Desporto. Parâmetros curriculares nacionais: introdução aos parâmetros curriculares nacionais. Brasília, 1998a.

. Ministério da Educação e do Desporto. Parâmetros curriculares nacionais: apresentação dos temas transversais. Brasília, 1998b.

. Ministério da Educação e do Desporto. Parâmetros curriculares nacionais: ciências naturais: ensino de quinta a oitava séries. Brasília, 1998c.

CACHAPUZ, A.; PRAIA, J.; JORGE, M. Da educação em ciências às orientações para o ensino das ciências: um repensar epistemológico. Ciência \& Educação, Bauru, v. 10, n. 3, p. 363-381, 2004.

CHASSOT, A. Alfabetização científica: questões e desafios para a educação. Ijuí: Unijuí, 2000.

DELIZOICOV, D.; ANGOTTTI, J. A.; PERNAMBUCO, M. M. Ensino de ciências: fundamentos e métodos. 2. ed. São Paulo: Cortez, 2002.

FOUREZ, G. Alfabetización científica y tecnológica: acerca de las finalidades de la enseñanza de las ciencias. Buenos Aires: Ediciones Colihue, 1994.

KRASILCHIK, M.; MARANDINO, M. Ensino de ciências e cidadania. São Paulo: Moderna, 2004.

LUJÁN LÓPEZ, J. L.; LÓPEZ CEREZO, J. A. Educación CTS en acción: enseñanza secundaria y universidad. In: GONZÁLEZ GARCÍA, M. I; LÓPEZ CEREZO, J. A.; LUJÁN LÓPEZ, J. L. (Org.). Ciencia, tecnología y sociedad: una introducción al estudio social de la ciencia y la tecnología. Madrid: Editorial Tecnos, 1996. p. 225-252.

MALDANER, O. A.; ZANON, L. B. Situação de estudo: uma organização do ensino que extrapola a formação disciplinar em ciências. In: MORAES, R.; MANCUSO, R. (Org.).

Educação em ciências: produção de currículo e formação de professores. Ijuí: Ed. Unijui, 2004. p. 43-64.

MALDANER, O. A. et al. Currículo contextualizado na área de ciências da natureza e suas tecnologias: a situação de estudo. In: ZANON, L. B.; MALDANER, O. A. (Org.).

Fundamentos e propostas de ensino de química para a educação básica no Brasil. Ijuí: Ed. Unijui, 2007. p. 109-138. 
Mundim, J. V.; Santos, W. L. P.

MUNDIM, J. V. Avaliação da abordagem de um tema CTS em aulas de ciências das séries finais do ensino fundamental: análise de uma intervenção pedagógica. 2009. 129 f. Dissertação (Mestrado em Educação) - Faculdade de Educação, Universidade de Brasília, Brasília, 2009.

RATCLIFFE, M.; GRACE, M. Science education for citizenship: teaching socioscientific issues. Maidenhead: Open University Press, 2003.

SAMAGAIA, R.; PEDUZZI; L. O. Q. Uma experiência com o projeto Manhattan no ensino fundamental. Ciência \& Educação, Bauru, v. 10, n. 2, p. 259-276, 2004.

SANTOS, W. L. P. dos. Educação científica na perspectiva de letramento como prática social: funções, princípios e desafios. Revista Brasileira de Educação, Rio de Janeiro, v. 12, n. 36, p. 474-492, 2007.

. Educação científica humanística em uma perspectiva freireana: resgatando a função do ensino de CTS. Alexandria: Revista de Educação em Ciência e Tecnologia, Florianópolis, v. 1, n. 1, p. 109-131, 2008.

SANTOS, W. L. P.; MORTIMER, E. F. Uma análise de pressupostos teóricos da abordagem C-T-S (Ciência-Tecnologia-Sociedade) no contexto da educação brasileira. Ensaio: Pesquisa em Educação em Ciências, Belo Horizonte, v. 2, n. 2, p. 133-162, 2000.

Abordagem de aspectos sociocientíficos em aulas de ciências: possibilidades e limitações. Investigações em Ensino de Ciências, Porto Alegre, v. 14, n. 2, p. 191-218, 2009.

SANTOS, W. L. P.; SCHNETZLER, R. P. Ciência e educação para a cidadania. In: CHASSOT, A.; OLIVEIRA, R. J. (Org.). Ciência, ética e cultura na educação. São Leopoldo: Editora Unisinos, 1997. p. 255-270. 2010. Educação em química: compromisso com a cidadania. 4. ed. Ijuí: Ed. Unijuí,

SOLOMON, J. Knowledge, values and public choice of science knowledge. In: ;

AIKENHEAD, G. (Org.). STS education: international perspectives on reform. New York: Teachers College Press, 1994. p. 187-193.

WAKS, L. J. Educación en ciencia, tecnología y sociedad: orígenes, desarrollos internacionales y desafíos intelectuales. In: MEDINA, M.; SANMARTIN, J. (Org.). Ciencia, tecnología y sociedad, estudios interdisciplinares en la universidad, en la educación y en la gestión pública. Barcelona: Anthropos, 1990. p. 42-75.

YAGER, R. The science, technology, society movement. Washington: National Science Teachers Association, 1993.

YUS, R. Temas transversais: em busca de uma nova escola. Porto Alegre: ArtMed, 1998.

Artigo recebido em 25/10/2011. Aceito em 20/05/2012. 